\title{
CFD SIMULATION OF CAPILLARY RISE OF LIQUID IN CYLINDRICAL CONTAINER WITH LATERAL VANES
}

\author{
XIAOLIN LIU \\ College of Aerospace Science and Engineering \\ National University of Defense Technology \\ Changsha China \\ zf251801775@163.com \\ YIYONG HUANG and GUANGYU LI \\ College of Aerospace Science and Engineering \\ National University of Defense Technology \\ Changsha China
}

Published 22 June 2016

\begin{abstract}
Orbit refueling is one of the most significant technologies, which has vital strategic meaning. It can enhance the flexibility and prolong the lifetime of the spacecrafts. Space propellant management is one of the key technologies in orbit refueling. Based on the background of space propellant management, CFD simulations of capillary rise of liquid in Cylindrical container with lateral vanes in space condition were carried out in this paper. The influence of the size and the number of the vanes to the capillary flow were analyzed too. The results can be useful to the design and optimization of the propellant management device in the vane type surface tension tank.
\end{abstract}

Keywords: Microgravity; vane-type surface tension tank; numerical simulation; design of vane-type surface tension tank.

\section{Introduction}

In the space environment, because the influence of gravity is very small, the propellant in tank is distributed irregularly. Surface tension tank using the surface tension to manage the propellant in the tank, separate the liquid and gas, and prevent the effect of jet-induced geyser when the propellant in the process of filling. It has high reliability, reusable feature ${ }^{1}$. So vane-type propellant management device (PMD) has been used in space applications for many years as a source of gas free liquid acquisition (anywhere from the Viking Orbiter to current communication satellite ${ }^{2-3}$ ), and will be planned for more applications in the future. Therefore, the optimization and design of surface tension tank is of great importance for the on-orbit refueling progress.

This is an Open Access article published by World Scientific Publishing Company. It is distributed under the terms of the Creative Commons Attribution 3.0 (CC-BY) License. Further distribution of this work is permitted, provided the original work is properly cited. 
The performance analysis of surface tension tank can be taken through two approaches, one is CFD analog simulation, and another is microgravity experiment. CFD analog simulation is a simple and shortcut approach to predict and calculate the flow behavior of propellant in the surface tension tank. However, microgravity experiment is necessary in order to eliminate the influence of those unpredictable factors. In this article, we use the Fluent software to simulation the capillary flow in a cylindrical tank with lateral in different numbers and sizes. The influence of numbers and sizes of vanes on the capillary flow in the tank is analyzed. Compared with the result of the drop tower experiment, the errors of simulation experiment were analyzed, which provides a reference to the design and optimization of the propellant management device in the vane type surface tension tank.

\section{Physical model}

The physical model of the CFD analog simulation and drop tower experiment is a cylindrical tank with a $15 \mathrm{~mm}$ wide lateral vane model, and its inner diameter is $30 \mathrm{~mm}$. The vane is installed on the vessel wall vertically, constituting the asymmetric interior corner. The physical model is shown in Figure 1 and the parameters of the physical model are shown in Table 1.

Table1. Parameters of the physical model

\begin{tabular}{ll}
\hline Inner diameter & Height \\
\hline $30 \mathrm{~mm}$ & $100 \mathrm{~mm}$ \\
\hline
\end{tabular}

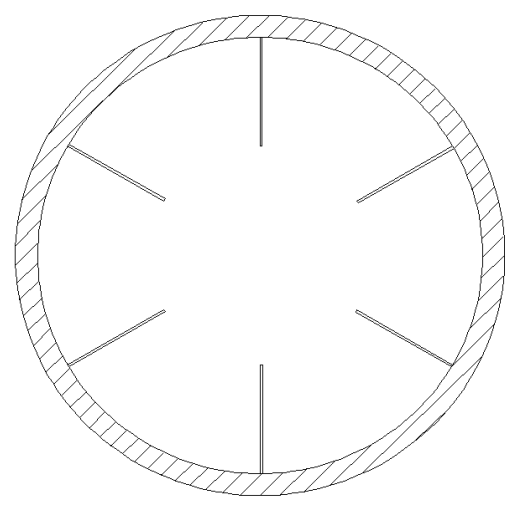

Fig. 1. 2D model for CFD simulation.

The different amounts and sizes of vanes in capillary flow simulation experiment used, and the specific parameters are shown in Table 2. 
Table 2. Different numbers and sizes of vanes

\begin{tabular}{lll}
\hline Serial number & Vane amounts & Vane sizes \\
\hline Tank one & 6 & $15 \mathrm{~mm} \times 3 \mathrm{~mm}$ \\
Tank two & 6 & $15 \mathrm{~mm} \times 3.9 \mathrm{~mm}$ \\
Tank three & 6 & $15 \mathrm{~mm} \times 2 \mathrm{~mm}$ \\
Tank four & 5 & $15 \mathrm{~mm} \times 3 \mathrm{~mm}$ \\
\hline
\end{tabular}

The fuel simulated in the tank is substituted by alcohol, and its properties are shown in Table 3.

Table 3. Properties of the alcohol

\begin{tabular}{|c|c|c|c|}
\hline Density & $\left(\mathrm{kg} / \mathrm{m}^{3}\right)$ & Viscosity $\quad(\mathrm{kg} / \mathrm{m} \cdot \mathrm{s})$ & Surface tension $\quad(\mathrm{N} / \mathrm{m})$ \\
\hline 790 & & 0.0012 & 0.022 \\
\hline
\end{tabular}

\section{Mathematical formulation and numerical method}

\subsection{Control equation}

The commercial code ANSYS FLUENT 14.0 is used for the numerical simulations. The three-dimensional VOF model is used to address the gas-liquid two-phase flow and free surface flow problems, in which fluid volume function and its control equation are introduced to present the density of mixed fluid and track the position of free surface. When the fluid flow is laminar in the tank, the basic equation of VOF model consists of density equation, continuity equation and momentum equation ${ }^{4}$.

(1) Density equation

The flow in the tank only have gas-liquid two-phase. Then the density equation is as follows:

$$
\begin{gathered}
\rho=\partial_{1} \rho_{1}+\partial_{2} \rho_{2} \\
\partial 1+\partial 2=1
\end{gathered}
$$

$\rho$-the density of mixed phase; $\rho_{1}, \rho_{2}$ - the densities of two corresponding phases; $\partial_{1}, \partial_{2}$ - the volume fractions of two corresponding phases;

(2) Continuity equation

Continuity equation is as follows:

$$
\frac{\partial \rho}{\partial t}+\frac{\partial}{\partial x}(\rho u)=R
$$

$u$ - the velocity of mixed fluid; $R$ - the constant, can be ignored. 
(3) Momentum equation

$$
\frac{\partial}{\partial t}\left(\rho u_{j}\right) \frac{\partial}{\partial x_{i}}\left(\rho u_{j} u_{i}\right)=-\frac{\partial p}{\partial x_{j}}+\mu \frac{\partial}{\partial x_{i}}\left(\frac{\partial u_{i}}{\partial x_{j}}+\frac{\partial u_{j}}{\partial x_{i}}\right)+\rho g_{i}
$$

Surface tension equation is:

$$
\frac{\partial p}{\partial x_{j}}=-\sigma \frac{\partial}{\partial x_{j}}\left(\frac{1}{r}\right)
$$

$r$-the radius of curvature; $\sigma$-the surface tension coefficient. Momentum equation of mixed fluid is obtained, when substituting surface tension equation into three equations.

\subsection{Mesh generation}

A hexagonal mesh is generated by using the blocking technique in the ICEM software. The whole grid number of the calculation model is about 500 thousands. In order to make the results more accurate, we refine the grid near the wall. The mesh generation of the model is shown in Figure 2.

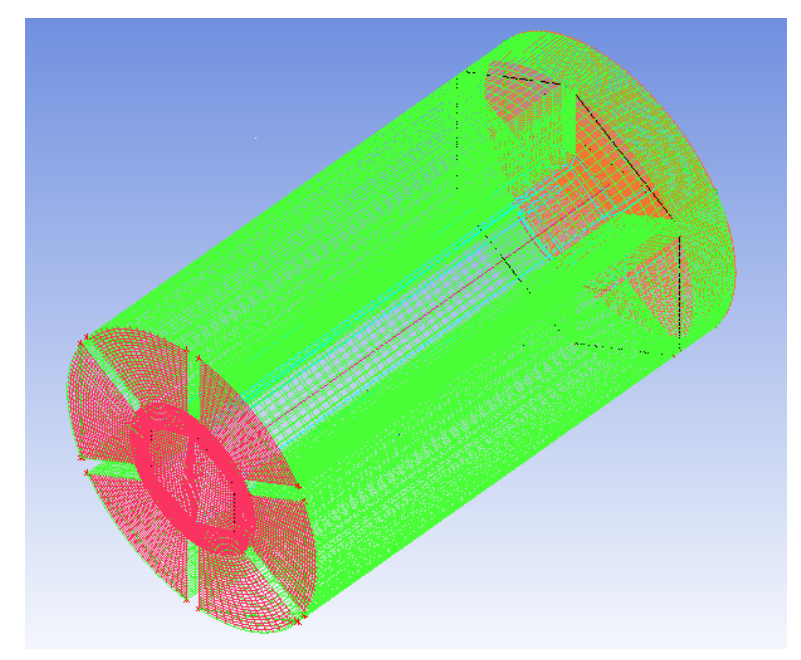

Fig. 2. Mesh generation of the model.

\subsection{Simulation conditions}

Assuming that the solid wall boundary condition applies to each wall of the tank, the logarithmic function describing the flow of the liquid near the wall is based on generalized no-penetration boundary condition and no-slip boundary condition with a $10^{\circ}$ liquid-solid contact angle.

There exists two phases in the tank. The basic phase is gas phase and the second phase is alcohol phase. When the flow is simulated by the VOF multiphase flow model, the volumetric fraction and distributive configuration of both phases in computational 
domain is considered firstly. The alcohol phase occupies $1 / 10$ region of the cylindrical tank from the bottom, which is $10 \mathrm{~mm}$ deep in the tank.

Considering the situation of satellite in space, the micro gravitational acceleration is vertical downward along the tank, and its magnitude is $9.8 \times 10^{-4} \mathrm{~m}^{2} / \mathrm{s}$.

In all the simulations, the QUICK scheme was used for the discretization of the momentum equation, the second-order implicit method was used for the discretization of the temporal derivatives, and the geometric reconstruction scheme was used for the interface reconstruction.

\section{Result and discussion}

\subsection{Comparison of the flow process in simulation and microgravity experiment}

Comparison diagram of flow process in simulation and microgravity experiment ${ }^{1}$ is shown in Figure 3. Fig. 3(a) is the simulation results, and Fig. 3(b) is the results of the drop tower experiment. As shown in the comparison diagram, flow characteristics of the fluid in the tank and the entirely escalated tendency along the solid wall agree with results of the drop tower experiment.

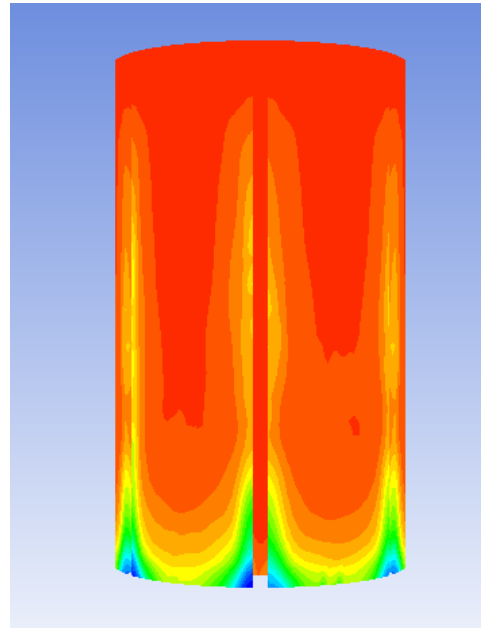

(a)

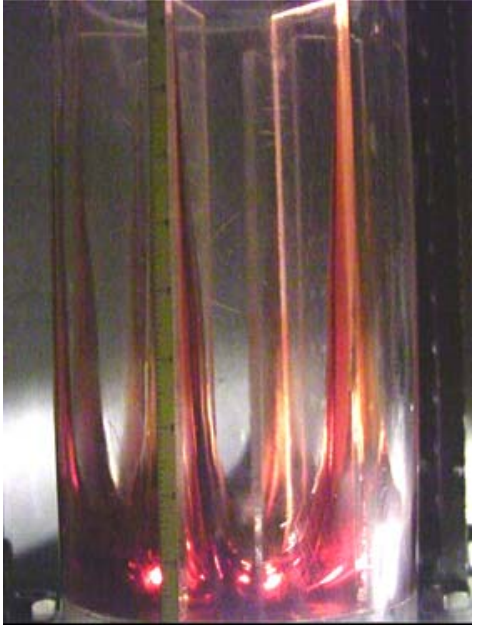

(b)

Fig. 3. Simulation result and experience result.

The change of liquid surface height over time in simulation and microgravity experiment is shown in Figure 4. It can be seen that the results are similar, and the average error of simulation value and experiment value is $7.09916 \%$, which is within acceptable range. Besides, the liquid surface tips are so tiny that the highest point of liquid surface is difficult to determine. Then the surface mesh generation is not dense enough, which also influences the determination of the liquid surface height. By considering all the factors, flow characteristics and flow tendency of the fluid in the tank 
agree well with results of the drop tower experiment. So it is concluded that the simulation model is valid.

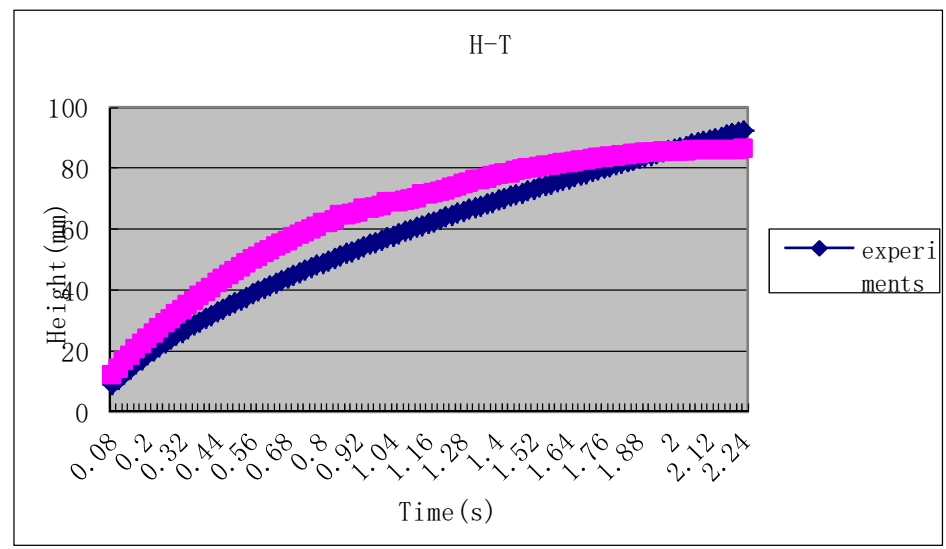

Fig. 4. Experimental and numerical results.

\subsection{Comparison of simulation results using different width vanes}

The fluid flow condition in the tank with three different-width vanes was simulated, and the simulation results were discussed. The simulation cloud maps of fluid flow condition and the change of liquid surface height over time in the tank with three different-width vanes are shown in Figures 5 and 6, respectively. As shown in the figures, the flow trends of the fluid between the vanes and tank wall in three conditions are basically the same. However, the final liquid surface height is inversely proportional to the width of the vane. The wider the baffle is, the lower the final liquid surface height is.

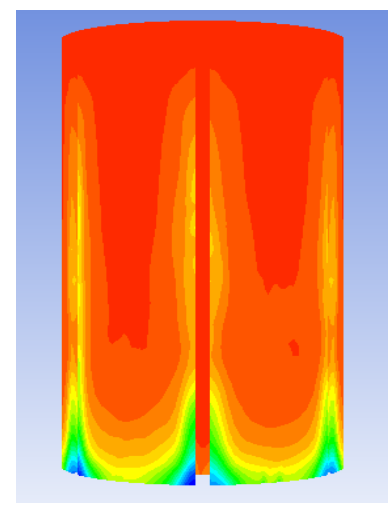

Tank one

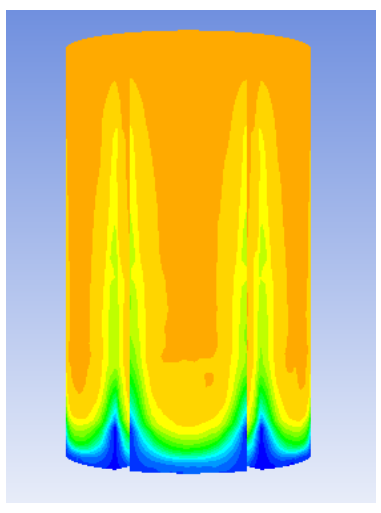

Tank four

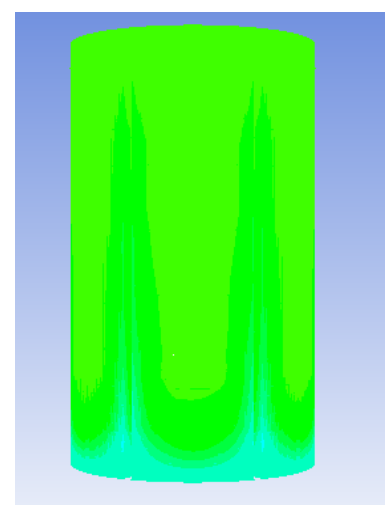

Tank five

Fig. 5. Simulation results. 


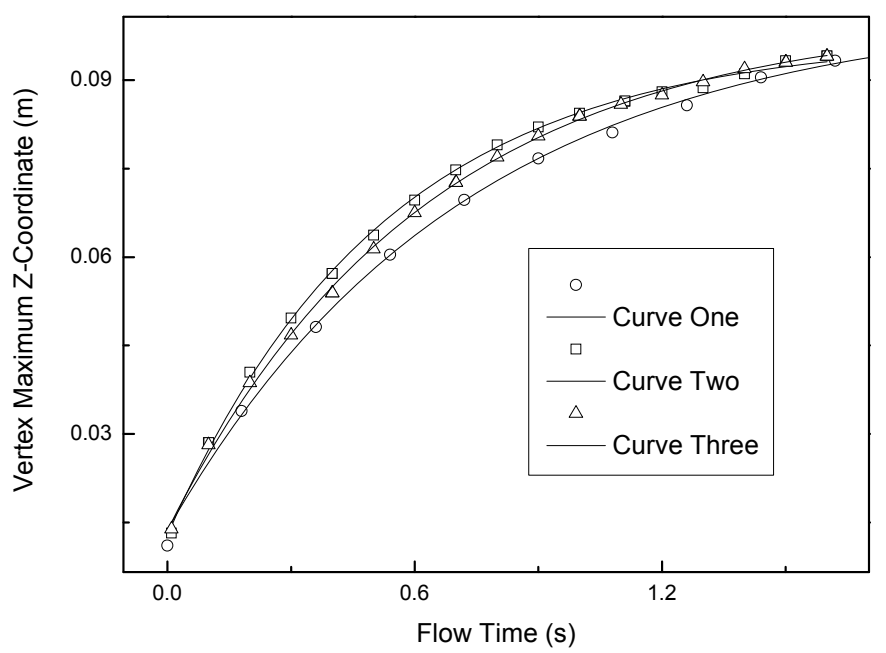

Fig. 6. Simulation result.

\subsection{Comparison of simulation results using different amount vanes}

The simulation contours maps of fluid flow condition and the change of liquid surface height over time in the tank with different amounts vanes are shown in Figures 8 and 9, respectively. As shown in the figures, it is obvious that the flow trends of the fluid between the vanes and tank wall in two conditions are also basically the same. Besides, the final liquid surface height is in inverse proportion to the amount of vane. As the baffle is installed vertically on the tank wall, the equivalent interior angle changes little with the increase of numbers of the vanes, which does not greatly affect the flow condition. However, as the number of the vanes increases, the curvature radius decreases, so it is the same as the liquid surface height. In particular, the liquid surface height with five vanes is lower than that with six vanes, due to the limit of the width. With smaller chord tangent angle and more rapid capillary flow, the tank with six vanes is the most optimal project of those. 

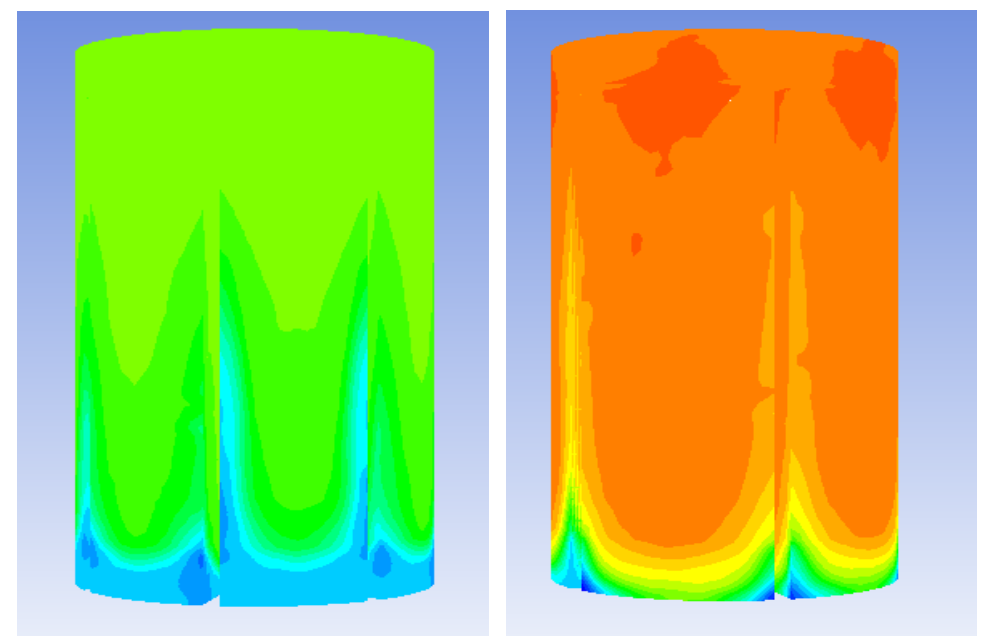

Fig. 7. Simulation results.

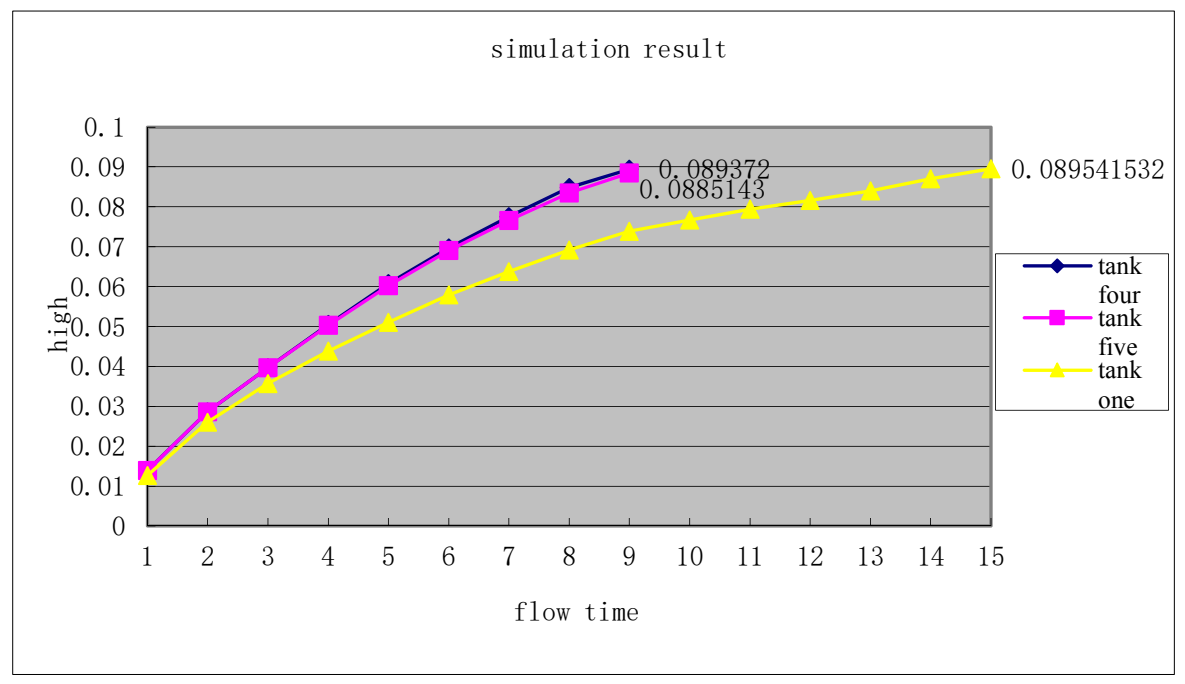

Fig. 8. Simulation result.

\section{Conclusions}

Flow condition of the fluid in cylindrical container with lateral vanes was simulated, and the microgravity drop tower experiment had been carried out. Compared with the simulation results, the drop tower experiment results fit in nicely, although there are some errors. In section four, we explained the discrepancy between the simulation results and 
experiment values and analyzed the simulation results with different numbers and width vanes. The flow characteristics and distribution law of the fluid in the tank under microgravity are obtained.

The simulation results show that the flow condition in the tank basically agrees with that in the microgravity drop tower experiment. With the decrease of the width of the vanes, the liquid surface height increases fast. Besides, the influence of the number of the vanes to the capillary flow is not clear, however, in this work, the liquid surface in the tank with six vanes increases faster than the others. In the end, the results can be useful to the optimization and design of the propellant management device in the vane type surface tension tank.

\section{References}

1. J. Li. The Study of Interior Corner Flow Theory and Application in the Design of Vane-type Surface Tension Tank [D]. Changsha: National University of Defense Technology, 2012.

2. Viking Orbiter 1975 System Support, Final Report, Part2, Propulsion Hardware, SE-009-47-01, JPL Contract 953261, Martin Marietta Corporation, Feb 1974.

3. J.R. Rollins, R.K. Grove. Design and Operational Performance of the INSAT-I Propellant tank. AIAA Paper 83-1273; 1983.

4. Q. Hu. Numerical Simulation and Experiment Verification of Fluid Behavior in the Vane Type Tank with Big Vanes in Microgravity Environment[C].

5. D.J. Chato, T.A. Martin. Vented Tank Resupply Experiment-Flight. AIAA-97-2815, 1997.

6. H.T. Walter, R.T. Jim. Design and manufacture of a propellant tank assembly. AIAA 97- 2813, 1997.

7. D.A. Bolleddula, Y. Chen, B. Semerjian. Compound Capillary Flows in Complex Containers-Drop Tower Test Results. Microgravity Sci. Technol. 2010, 22.

8. Y. Wei. Research on the Flow in the Process of the Propellant Management in a Spacecraft Tank under Microgravity [D]. Changsha: National University of Defense Technology, 2012.

9. Y. Chen, S. H. Collicottt. A Study of wetting in an asymmetrical vane-wall gap in propellant tanks. AIAA -2003-4893. Huntsville, Alabama, 2003.

10. M.M. Weislogel. Some Analytical Tools for Fluids Management in Space-Isothermal Capillary Flows along Interior Corners. Adv. Space Res. 2003, VOL. 32(No.2). 